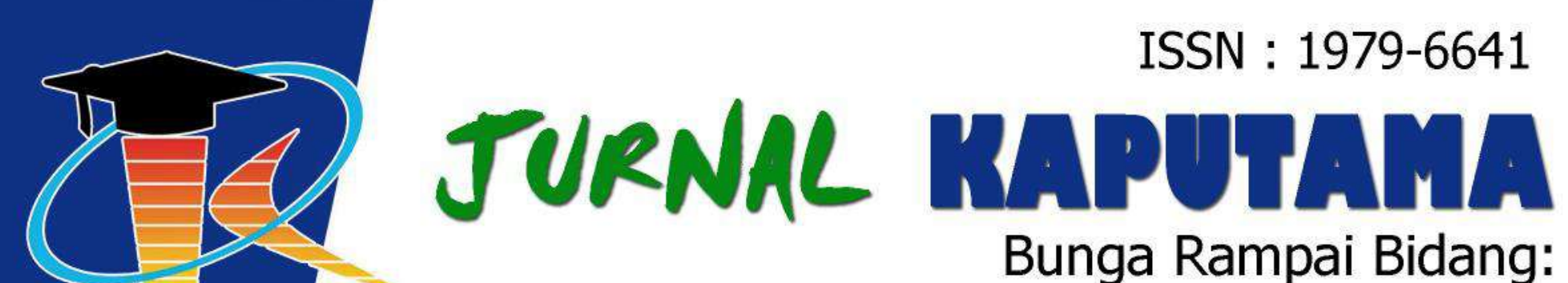

Manajemen Informatika, Sistem Informasi, Teknik Informatika,

Komputer dan Akuntansi

SISTEM PENGAMBILAN KEPUTUSAN PEMBERIAN BONUS PT. SINAR SOSRO DENGAN MENGGUNAKAN METODE AHP Akim Manaor Hara Pardede, Lina Arliana Nur Kadim Hal $1-7$

PERANCANGAN SISTEM PAKAR DIAGNOSA PENYAKIT TANAMAN KELAPA SAWIT DENGAN METODE BAYES (STUDI KASUS: PT. UKINDO BLANKAHAN ESTATE) Akim Manaor Hara Pardede, Novriyenni Hal 8- 17

SISTEM PAKAR DIAGNOSA PENYAKIT KANKER HATI DENGAN METODE CERTAINTY FACTOR Budi Serasi Ginting, Magdalena Simanjuntak Hal $18-28$

PEMETAAN LOKASI PEMBANGUNAN DI KABUPATEN LANGKAT DENGAN METODE CLUSTERING PADA BAPPEDA KABUPATEN LANGKAT Relita Buaton, Achmad Fauzi Hal $29-37$

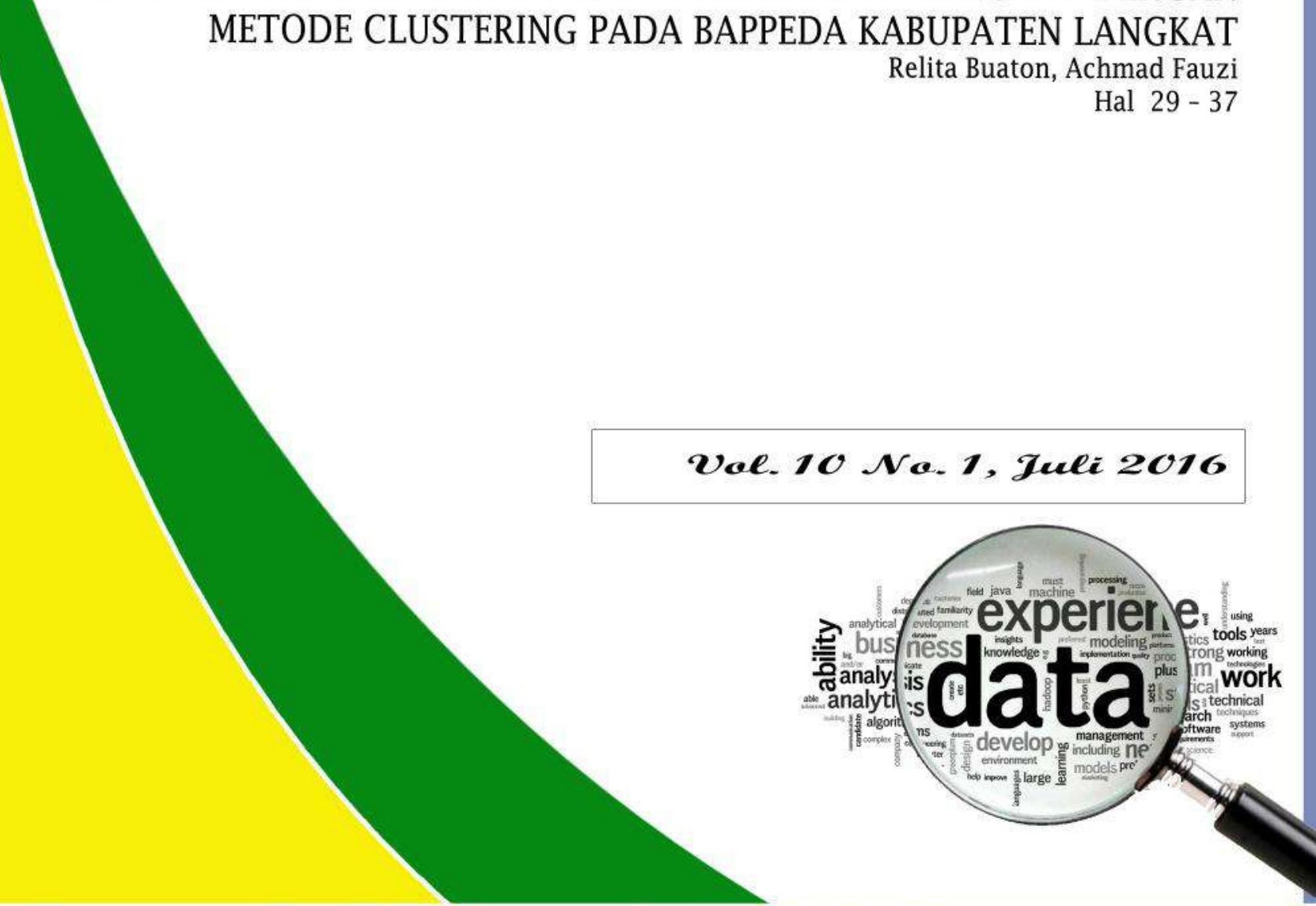

Jl. Veteran No. 4A - 9A Binjai, 20714, NorthSumatera, Indonesia

T. $061-8828840,8828841$ * F. $8828845 *$ M. 082366304242

W. www.kaputama.ac.id*E. info@kaputama.ac.id * FB. STMIKKAPUTAMA-BINJAI 


\title{
PERANCANGAN SISTEM PAKAR DIAGNOSA PENYAKIT TANAMAN KELAPA SAWIT DENGAN METODE BAYES STUDY KASUS PT.UKINDO BLANKAHAN ESTATE
}

\author{
Akim M.H. Pardede ${ }^{1}$, Novriyenni ${ }^{2}$ \\ STMIK KAPUTAMA, Jln. Veteran No. 4A-9A \\ Binjai, Indonesia
}

\begin{abstract}
Abstrak
Saat ini perkebunan kelapa sawit di Indonesia semakin berkembang, kelapa sawit tumbuh hampir diseluruh kepuluan Nusantara. Hampir seluruh bagian dari tanaman ini bermanfaat bagi kehidupan manusia. Semakin tinggi kebutuhan manusia, maka kebutuhan kelapa sawit semakin meningkat. Namun terjadi ketidak seimbangan dimana setiap tahun kebutuhan kelapa sawit semakin meningkat, sedangkan produksi kelapa sawit semakin menurun. Hal ini disebabkan ketidak pahaman petani terhadap jenis-jenis penyakit yang terdapat pada tanaman kelapa sawit yang dapat mengakibatkan kerusakan terus menerus pada tanaman ini. Salah satu metode yang cocok dalam penyeleksian tersebut adalah dengan mengunakan metode bayes. karena metode bayes ini merupakan metode yang baik didalam mesin pembelajaran berdasarkan data training dengan menggunakan probabilitas bersyarat sebagai dasarnya
\end{abstract}

Kata kunci : Kelapa Sawit, Bayes, Sitem Pakar

\section{PENDAHULUAN \\ 1.1 Latar Belakang}

Saat ini perkebunan kelapa sawit di Indonesia semakin berkembang, kelapa sawit tumbuh hampir diseluruh kepuluan Nusantara. Hampir seluruh bagian dari tanaman ini bermanfaat bagi kehidupan manusia. Semakin tinggi kebutuhan manusia, maka kebutuhan kelapa sawit semakin meningkat. Namun terjadi ketidak seimbangan dimana setiap tahun kebutuhan kelapa sawit semakin meningkat, sedangkan produksi kelapa sawit semakin menurun. Hal ini disebabkan ketidak pahaman petani terhadap jenis-jenis penyakit yang terdapat pada tanaman kelapa sawit yang dapat mengakibatkan kerusakan terus menerus pada tanaman ini.

Salah satu perusahaan yang memiliki lahan tanaman kelapa sawit yang cukup luas yaitu PT.UKINDO BLANKAHAN ESTATE yang merupakan perkebunan kelapa sawit swasta yang bergerak dalam produksi buah sawit, untuk mendapatkan buah sawit yang berkualitas maka harus memiliki tanaman kelapa sawit yang baik , tanaman kelapa sawit akan tumbuh dengan baik dan berproduksi secara optimal apabila tanaman tersebut dilindungi dari penyakit.

Melihat permasalahan diatas, perlu dikembangkan sistem pakar diagnosa penyakit tanaman kelapa sawit. Dengan adanya sistem pakar ini diharapkan petani dapat mengetahui jenis penyakit dan solusinya secara cepat sehingga masalah menurunnya produksi kelapa sawit dapat teratasi.

Salah satu metode yang cocok dalam penyeleksian tersebut adalah dengan mengunakan metode bayes. karena metode bayes ini merupakan metode yang baik didalam mesin pembelajaran berdasarkan data training dengan menggunakan probabilitas bersyarat sebagai dasarnya.

Penelitian ini di dukung oleh jurnal informatika vol 2, no. 2 Juli 2008 


\begin{tabular}{lll} 
dengan judul & \multicolumn{2}{c}{ PEMANFAATAN } \\
TEOREMA & BAYES DALAM \\
PENENTUAN PENYAKIT THT"
\end{tabular}
yang dibuat oleh sri winarti. Dalam hasil penelitiannya Sri Winiarti menyatakan bahwa sebuah perangkat lunak atau software baru tentang sistem pakar untuk mendiagnosa penyakit telinga, hidung dan tenggorokan menggunakan teorema bayes dapat memberikan kepastian kepada user akan peluang solusi yang diberikan sistem.

Untuk merealisasikan hal tersebut diatas penulis mencoba membuat rancangan sistem pakar berjudul "PERANCANGAN SISTEM PAKAR DIAGNOSA PENYAKIT TANAMAN KELAPA SAWIT DENGAN METODE BAYES STUDY KASUS PT.UKINDO BLANKAHAN ESTATE”.

\subsection{Rumusan Masalah Penelitian}

Dalam pembuatan dan perencanaan sistem ada masalah yang perlu diperhatikan diantaranya adalah:

1. Bagaimana mengenali dan mengetahui gejala penyakit tanaman kelapa sawit serta solusinya dengan menggunakan sistem pakar dan metode bayes?

2. Bagaiman cara memberikan informasi kepada petani kelapa sawit tentang jenis penyakitpenyakit yang dialami tanaman kelapa sawit?

3. Bagaimana menciptakan perangkat lunak yang dapat mendiagnosa penyakit tanaman kelapa sawit?

\subsection{Tujuan Penelitian}

Tujuan dari penelitian ini antara lain yaitu :

1. Untuk mengetahui penyakit tanaman kelapa sawit yang disebabkan oleh biotis (Parasit) berdasarkan gejala-gejala.

2. Untuk memberikan informasi tentang solusi penyakit pada tanaman kelapa sawit.
3. Untuk membangun aplikasi menggunakan metode bayes yang berbasis web.

\subsection{Manfaat Penelitian}

Manfaat yang dapat diambil dari penelitian ini adalah:

1. Dapat membantu petani mengetahui penyakit tanaman kelapa sawit dan solusinya.

2. Memberikan kemudahan bagi user untuk mendiagnosa penyakit tanaman kelapa sawit.

3. Sistem pakar ini dapat membantu pakar ketika tidak ditempat untuk mendiagnosa penyakit tanaman kelapa sawit.

4. Dengan online bisa digunakan user untuk dilihat oleh orang banyak tanpa dibatasi ruang dan waktu.

\section{TEORI DASAR}

\subsection{Pengertian Sistem}

Tahap perancangan sistem dilakukan setelah tahap analisis sistem dilakukan. Tujuan dari perancangan sistem adalah untuk memenuhi kebutuhan pemakai (user) mengenai gambar yang jelas tentang perancangan sistem yang akan dibuat serta diimplementasikan.

Menurut http://www elib. unikom.com di akses pada tanggal 08 September 2012 "perancangan sistem adalah suatu upaya untuk membuat suatu sistem yang beru atau memperbaiki sistem yang lama secara keseluruhan atau memeperbaiki sistem yang telah ada". Kegiatan-kegiatan yang dilakukan adalah:

1. Membuat rancangan sistem dan spesifikasi teknis

2. Membuat program-program komputer

3. Melatih pemakaian sistem

4. Merencanakan konfigurasi sistem

\subsection{Sistem Pakar}

Sistem pakar merupakan program komputer yang mampu 
menyimpan pengetahuan dan kaidah dari domain pakar yang khusus. Dengan bantuan sistem pakar seorang yang awan atau tidak ahli dalam suatu bidang tertentu akan dapat menjawab pertanyaan, menyelesaikan masalahan dan mengambil keputusan yang biasanya dilakukan oleh seorang pakar.

Menurut Muhammad Arhami (2005, h. 3) "sistem pakar adalah salah satu cabang dari AI yang membuat penggunaan secara luas knowledge yang khusu untuk menyelesaikan masalah tingkat manusia yang pakar". Seorang pakar adalah orang yang mempunyai keahlian dalam bidang tertentu, yaitu pakar yang mempunyai knowledge atau kemampuan khususnya yang orang lain tidak mengetahui atau mampu dalam bidang yang dimilikinya.

Ada bagian penting dari sistem pakar, yaitu lingkungan pengembangan (Development environment) dan lingkungan konsultasi (Consultation environment). Lingkungan pengembangan digunakan oleh pembuat sistem pakar untuk membangun komponen-komponennya dan memperkenalkan pengetahuan kedalam Knowledge base (basis pengetahuan). Lingkungan konsultasi digunakan oleh pengguna untuk berkonsultasi pengguna mendapat pengetahuan dan nasihat dari Sistem Pakar layaknya berkonsultasi dengan seorang pakar.

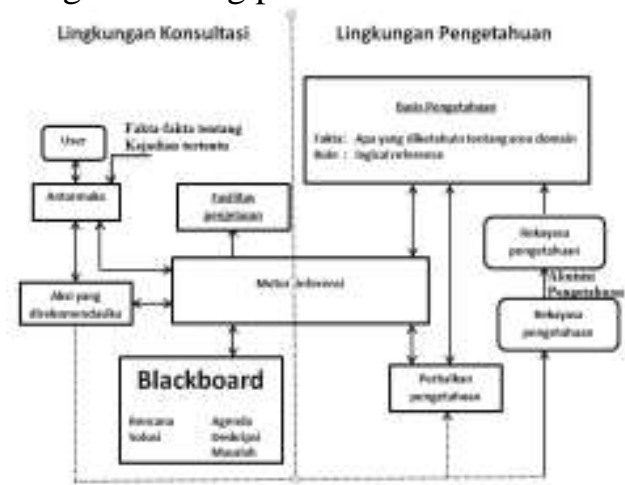

Gambar II. 1 Komponen-Komponen Yang Penting Dalam Sebuah Sistem Pakar

\subsection{Diagnosa}

Mendiagnosa organisasi merupakan salah satu komponen utama dalam melakukan perencanaan perubahan. Diagnosis adalah proses untuk mengerti suatu fungsi dari arus system, yang pada kegiatan tersebut melibatkan pengumpulan informasi bersangkutan tentang operasi organisasi yang sedang berjalan, meneliti data tersebut, dan menggambarkan penarikan kesimpulan untuk peningkatan dan perubahan yang potensial. Hasil diagnosa yang efektif menyediakan pengetahuan yang sistematis bagi organisasi untuk mendesain intervensi yang sesuai.

Kegiatan diagnosa ini biasanya dilakukan setelah adanya proses entering dan contracting yang dilakukan oleh organisasi untuk melakukan perencanaan perubahan, yang pada kedua proses tersebut organisasi telah menetapkan langkah untuk menindak lanjuti hasil diagnosa yang berhasil. Proses ini membantu praktisi pengembangan organisasi dan anggota klien (yang memakai konsultan perubahan) yang bersama-sama menentukan focus isu organisasi pada, bagaimana mengumpulkan dan menganalisis data untuk mengerti posisi organiassi, dan bagaimana bekerja bersama dalam mengembangkan langkah aksi dari diagnosa tersebut. Diagnosa dalam pengembangan organisasi, bagaimana pun merupakan banyak kolaborasi, seperti menyiratkan perpektif medis.

\subsection{Pengertian Tanaman Kelapa Sawit}

Kelapa sawit tumbuh hampir di seluruh kepulauan nusantara hampir seluruh bagian tanaman ini bermanfaat bagi kehidupan manusia.

Menurut Putranto Adi (2012, h. 17) Tanaman kelapa sawit adalah tanaman yang berbentuk pohon. Tingginya dapat mencapai 24 meter. Akar serabut tanaman kelapa sawit mengarah kebawah dan samping. Setelah itu juga dapat beberapa akar 
napas yang tumbuh mengarah kesamping atas untuk mendapatkan tambahan aerasi. Seperti jenis palma lainnya, daunnya tersusun majemuk menyirip. Daun bewarnah hijau tua dan pelepah bewarnah sedikit lebih muda. Penampilan agak mirip sedikit dengan tanaman salak, hanya saja dengan duri yang tidak terlalu keras dan tajam. Batang tanaman diselimutin dengan bekas pelepah hingga umur 12 tahun. Setelah umur 12 tahun pelepah yang mengiringi akan terlepassehingga penampilan akan mirip dengan kelapa.

\subsubsection{Faktor Pengendalian Penyakit Tanaman Kelapa Sawit}

Pengendalian penyakit tanaman pada hakikatnya merupakan tugas dan kewajibabn petani sendiri. Menurut Suyatno Risza (1994, h. 55)“'Dalam pengendalian penyakit perlu disadari bahwa penyakit tanaman kelapa sawit sulit diberantas bahkan hampir tidak mungkin dapat diobati dengan fungisida. Oleh karena itu pengendalian harus ditekankan pada tindakan pencegahan. Terutama penyakit Gonoderma sp. Sangat penting dicegah sejak mulai replanting. Bila pemberantasan dilakukan dengan menggunakan fungisida harus sungguhsungguh dipertimbangkan dengan hatihati".

\subsubsection{Jenis-jenis Penyakit Tanaman Kelapa Sawit}

1. Penyakit Busuk Pangkal Batang (Gonoderma Sp.)

2. Penyakit Busuk Tandan (Marasmius)

3. Penyakit tajuk (crown deseases)

4. Penyakit Bercak Daun

5. Penyakit Karat

6. Penyakit busuk pucuk kelapa sawit

7. Penyakit Cincin Merah (red ring disease)

8. Penyakit daun menguning

9. Penyakit Akar

\subsection{Probabilitas dan Metode Bayes}

Teori probabilitas Bayesian merupakan satu dari cabang teori statistik matematik yang memungkinkan kita untuk membuat satu model ketidakpastian dari suatu kejadian yang terjadi dengan menggabungkan pengetahuan umum dengan fakta dari hasil pengamatan.

Menurut

http://www.rolliawati.dosen.com diakses pada tanggal 11 November 2011, Probabilitas adalah hasil bagi dari banyaknya peristiwa yang mungkin terjadi dalam jangka panjang jika kondisi stabil

Probabilitas menunjukkan kemungkinan sesuau akan terjadi atau tidak

$$
\begin{gathered}
\mathrm{P}(\mathrm{HX})=\frac{\begin{array}{l}
\text { Jumlah kasus pada setiap } \\
\text { hipotensis }
\end{array}}{\text { Total kasus keseluruan }} \\
\begin{array}{c}
\text { Probabilitas setiap gejala untuk } \\
\text { setiap hipotensis menggunakan rumus. }
\end{array} \\
\mathrm{P}(\mathrm{Ex} \mid \mathrm{HX})=\frac{\begin{array}{l}
\text { Frekuensi munculnya } \\
\text { evidence E pada Kasus }
\end{array}}{\text { Hipotensis } \mathrm{x}} \\
\text { Total kasus Hipotensis } \mathrm{x}
\end{gathered}
$$

Menghitung nilai kepercayaan ( ratio probabilitas ) Evidence E terhadap setiap hipotensis menggunakan rumus .

$$
\begin{aligned}
& \mathrm{P}(\mathrm{E} \mid \mathrm{Hi}) \mathrm{X} \mathrm{P}(\mathrm{Hi})
\end{aligned}
$$

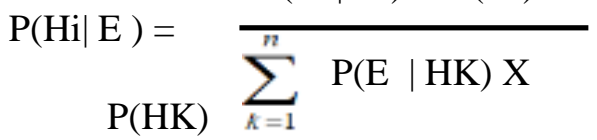

Untuk seluruh Hipotensis menggunakan rumus :

$$
\begin{aligned}
& \mathrm{P}(\mathrm{E} 1 \mid \mathrm{Hi}) * \\
& \mathrm{P}(\mathrm{E} 2 \mid \mathrm{Hi}) * \\
& \ldots . \ldots \ldots \ldots . . . . . . . \\
& \mathrm{P}(\mathrm{EM} \mid \mathrm{Hi}) * \\
& \mathrm{P}(\mathrm{Hi})
\end{aligned}
$$

$\mathrm{P}(\mathrm{Hi} \mid \mathrm{E} 1, \mathrm{E} 2, \mathrm{E} 3)=,\overline{\sum_{k=1}^{n} \mathrm{P}(\mathrm{E} 1 \mid \mathrm{HK}) *}$ 


P(HK)

Keterangan:

$\mathrm{p}(\mathrm{Hi} / \mathrm{E})=$ probabilitas hipotesis $\mathrm{Hi}$ benar jika diberian evidence (fakta) $\mathrm{E}$

$\mathrm{p}(\mathrm{E} / \mathrm{Hi})=$ probabilitas munculnya evidence (fakta) E jika diketahui hipotesis Hi benar

$\mathrm{p}(\mathrm{Hi})=$ probabilitas hipotesis $\mathrm{Hi}$ (menurut hasil sebelumnya) tanpa memandang

evidence (fakta) apapun

$\mathrm{n} \quad=$ jumlah hipotesis yang mungkin

\section{METODOLOGI PENELITIAN}

\section{1}

\subsection{Perancangan diagram-diagram UML yang berjalan \\ Use Case diagram untuk} mendeskripsikan apa yang seharusnya dilakukan oleh sistem. Diagram use case menyediakan cara mendeskripsikan pandang eksternal terhadap sistem dan interkasi-interaksinya dengan dunia luar.

1. Use Case Diagram

Pada rancangan aplikasi yang dibuat, terdapat dua aktor yaitu aktor administrator dan petani,dimana administrator dan petani tersebut berinteraksi dengan sistem melalui fungsi-fungsi yang dimiliki oleh sistem.

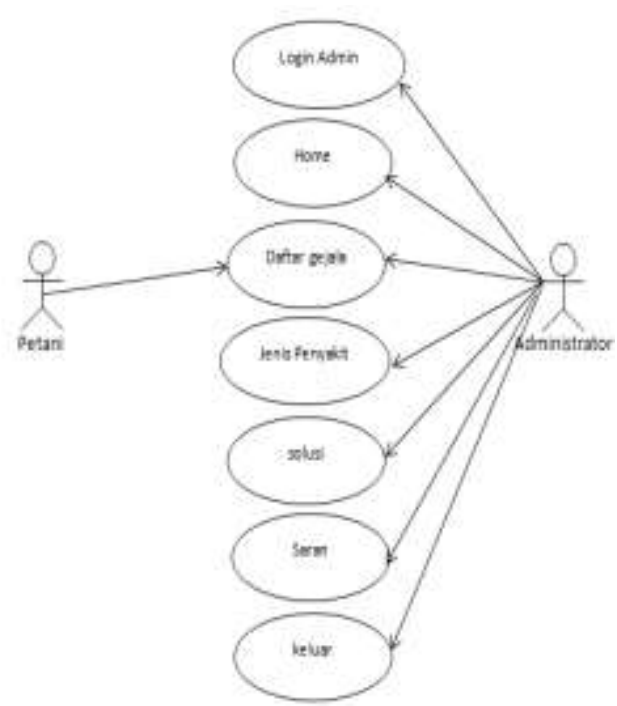

Gambar III. 3 Use Case Diagram Administrator

2. Sequence Diagram

Pada rancangan aplikasi yang dibuat, satu aktor yaitu aktor user, dimana user tersebut berinteraksi dengan sistem melalui fungsifungsi yang dimiliki oleh sistem.

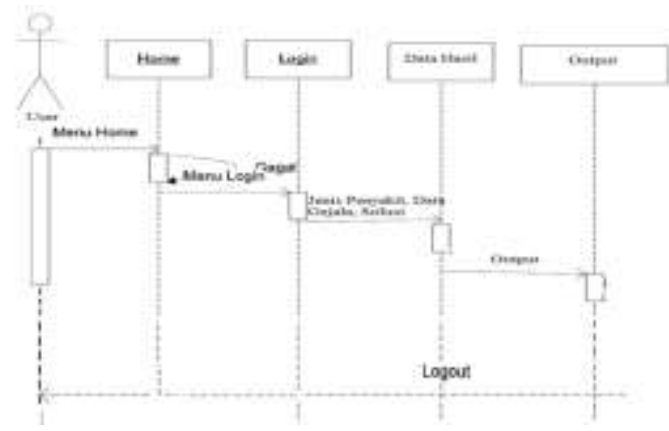

Gambar III. 5 Diagram Sequence yang Berjalan.

3. Diagram Class

Diagram Class adalah dekripsi kelompok obyek-obyek dengan property, perilaku (operasi) dan relasi yang sama. Sehingga dengan adanya class diagram dapat memberikan pandangan umum sebuah sistem. Adapun class diagram pada Sistem Pakar Diagnosa Penyakit Tanaman Kelapa Sawit sebagai berikut: 


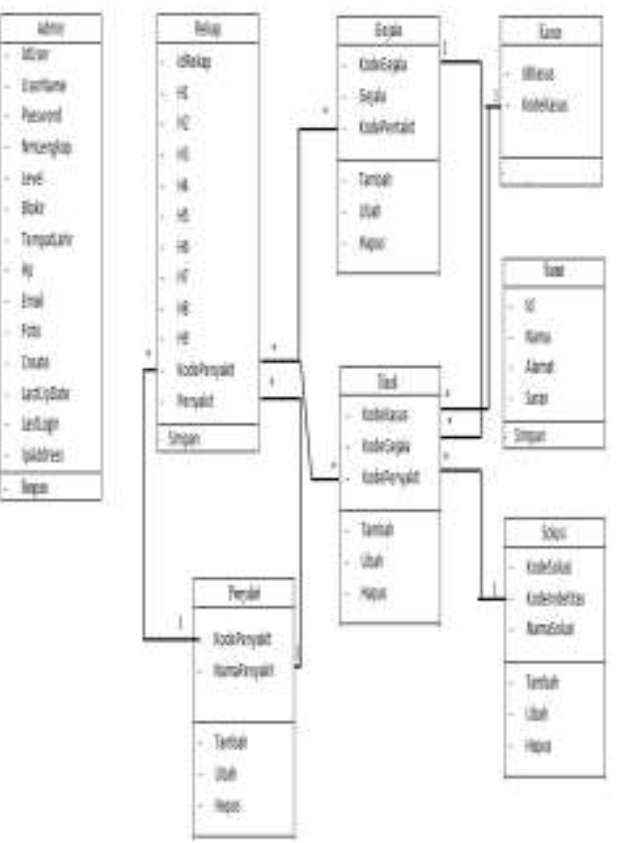

Gambar III. 6 Diagram Class

\section{Perancangan Antarmuka}

Agar data yang dibutuhkan oleh sistem dan data-data yang dihasilkan oleh sistem dapat diketahui oleh user maka pada pembuatan perangkat lunak ini membutuhkan beberapa From. Fromfrom yang dibutuhkan pada pembuatan perangkat lunak adalah sebagai berikut :

1. Rancangan Tampilan utama yang digunakan untuk menampilkan menu perangkat lunak From informasi sistem pakar yang digunakan untuk mengetahui tentang sistem pakar.

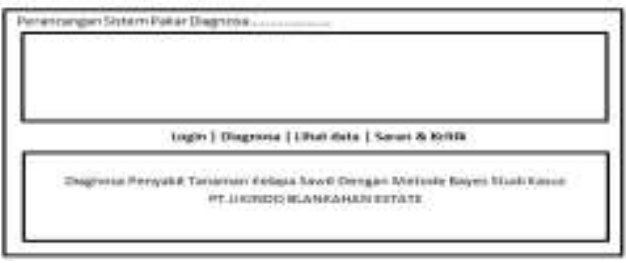

Gambar III. 9 Rancangan Tampil Utama dan Menu Informasi Sistem Pakar

2. Rancangan Tampilan Login Admin digunakan untuk mengisi username dan password agar admin bisa mengakses aplikasi tersebut.

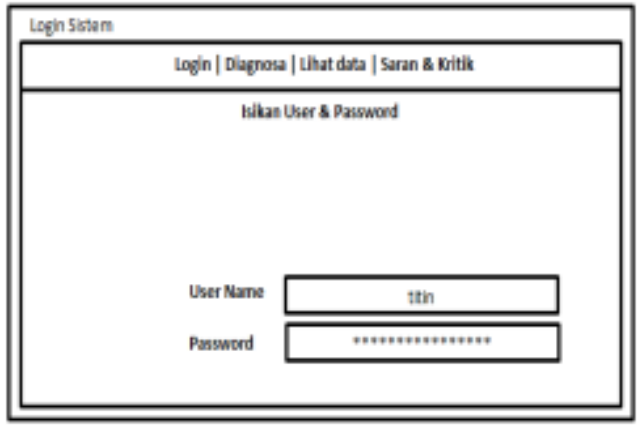

Gambar III. 10 Rancangan Login Admin

3. Rancagan input Diagnosa yang digunakan untuk memproses data kode kasus, nama penyakit, dan daftar gejala yang akan diinput untuk menghasilkan nilai dari masing-masing probabilitas setiap gejala yang sering muncul.

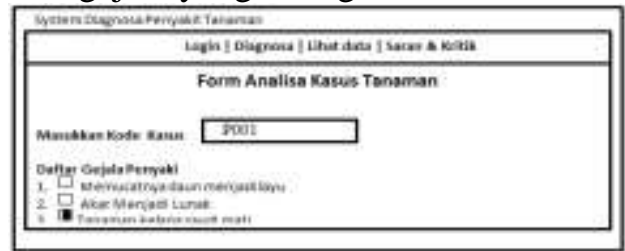

Gambar III. 11 Rancangan Input Diagnosa

4. Rancangan Output Lihat Data dan Hasil Out put digunakan untuk mengetahui Hasil Probabilitas dari masing-masing gajala yang telah diproses dalam menu diagnosa dan mengetahui hasil diagnosa penyakit.

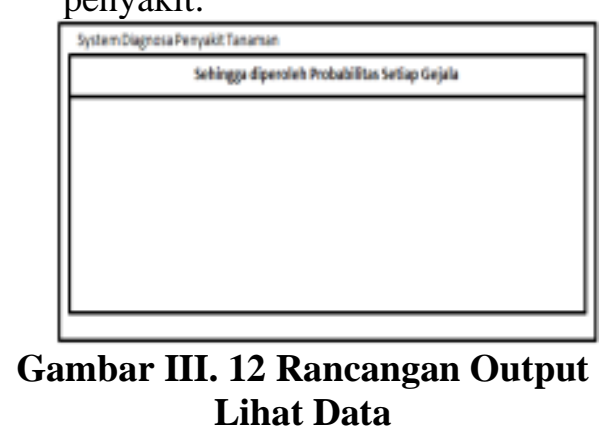

4. HASIL DAN PEMBAHASAN

4.1 Implementasi

Implementasi sistem adalah prosedur yang dilakukan untuk menyelesaikan desain sistem yang ada pada dokumen, desain sistem yang disetujui dan 
menguji, menginstal dan mulai menggunakan sistem yang baru. Pada implementasi ini terlebih dahulu dilakukan pengujian sistem. Setelah terlihat kesalahan dan permasalahan yang telah ditemukan di dalam pengujian, sistem tersebut diperbaiki kemudian pengujian sistem ini dilanjutkan ke tahap operasi yang nyata.

Pada tahap implementasi proses yang pertama kali dilakukan adalah pengkodean yang mengubah setiap desain yang dihasilkan ke dalam bentuk suatu bahasa pemrograman yang dapat dimengerti oleh komputer. Implementasi aplikasi disini lebih menjelaskan bagaimana proses penyeleksian calon penerima bantuan siswa miskin dari penginputan data siswa sampai output yang dikeluarkan oleh sistem pendukung keputusan. Berikut merupakan tujuan dari implementasi sistem :

1. Menyelesaikan sistem yang ada di dokumen desain yang disetujui.

2. Menulis menguji dan mendokumentasikan programprogram dan prosedur yang diperlukan oleh dokumen desain yang disetujui.

3. Memastikan bahwa pengguna dapat mengoperasikan sistem yang baru, yaitu dengan memberikan pelatihan bagi pengguna.

4. Memperhitungkan bahwa sistem memenuhi permintaan pemakai, yaitu dengan menguji sistem secara menyeluruh.

5. Memastikan sistem baru dapat berjalan dengan lancar yaitu dengan merencanakan, mengontrol dan melakukan instalasi dengan benar.

Untuk mewujudkan sistem yang telah dirancang dapat berjalan dengan baik maka diperlukan fasilitas-fasilitas penunjang lain yang secara prinsipnya biasa disebut sebagai aspek teknis sebagai berikut :

1. Hardware.

2. Software.

3. Brainware.

\subsection{Manual Program}

Berikut ini merupakan menumenu yang terdapat dalam sistem pakar diagnosa penyakit tanaman kelapa sawit.

1. From Utama

From utama yang digunakan untuk menampilkan menu perangkat lunak From informasi sistem pakar yang digunakan untuk mengetahui tentang sistem pakar.

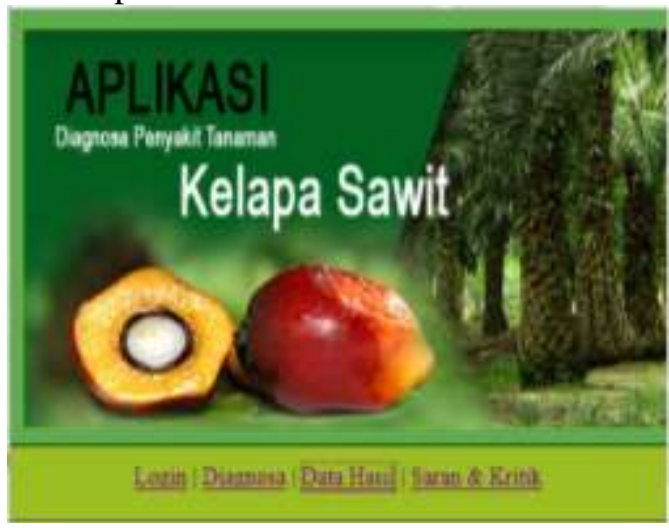

\section{Gambar IV. 1 Tampilan From \\ Utama dan Menu Informasi Sistem Paka}

2. Menu Login

Halaman Form Login merupakan form yang digunakan untuk mengisi username dan password agar admin bisa mengakses aplikasi tersebut.

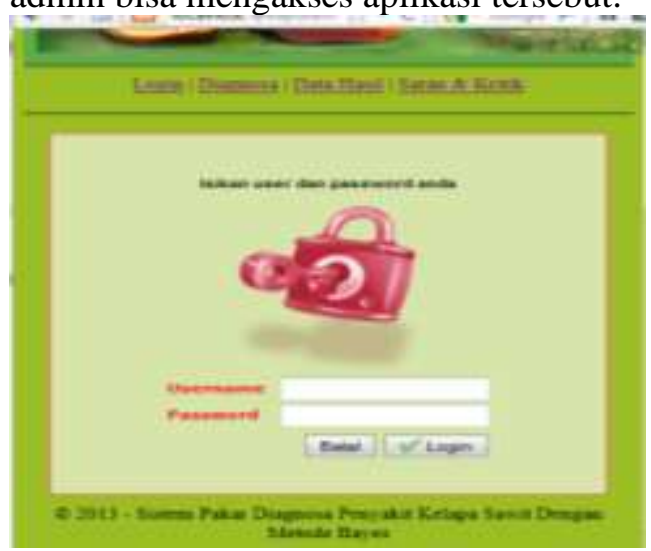

Gambar IV. 2 Form Login

\section{From Input Gejala}

From Input Gejala yang digunakan untuk memproses data kode kasus, nama penyakit, dan daftar gejala yang telah pilih untuk menghasilkan nilai dari masing-masing probabilitas setiap gejala yang sering muncul. 


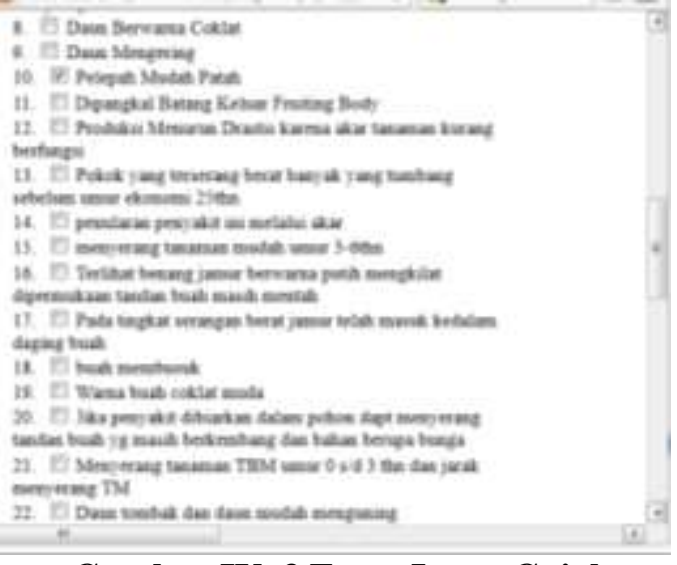

Gambar IV. 3 Form Input Gejala

4. From Lihat Data dan Output

From Lihat Data dan Output digunakan untuk mengetahui Hasil Probabilitas dari masing-masing gajala yang telah diproses dalam menu diagnosa dan hasil mengetahui nama penyakit yang dialamin tanaman kelapa sawit dengan membandingkan setiap nilai dari masing-masing penyakit nilai yang terbesar adalah nilai yang terdiagnosa .

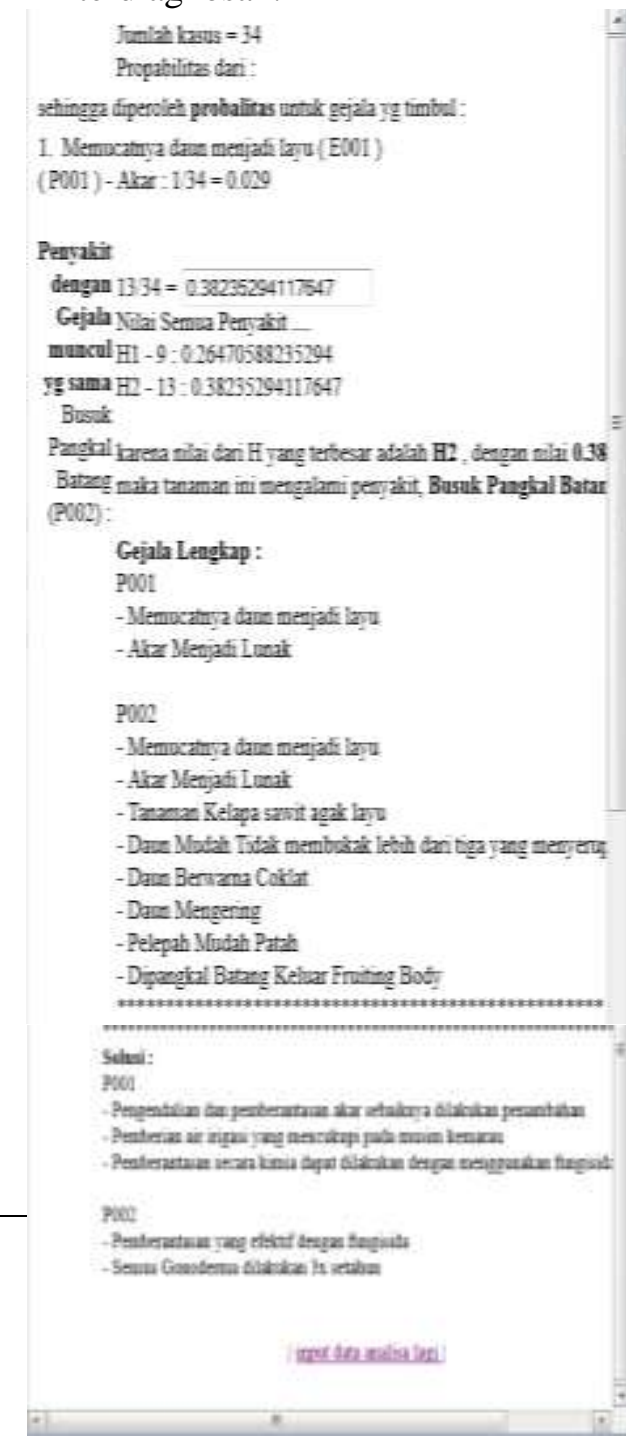

\section{Gambar IV. 4 From Lihat Data Dan Output}

5. Menu Saran dan Kritik

From Saran dan Kritik digunakan untuk mengetahui kritik dan saran terhadap program ini. Berikut tampilan proses dari form saran dan kritik

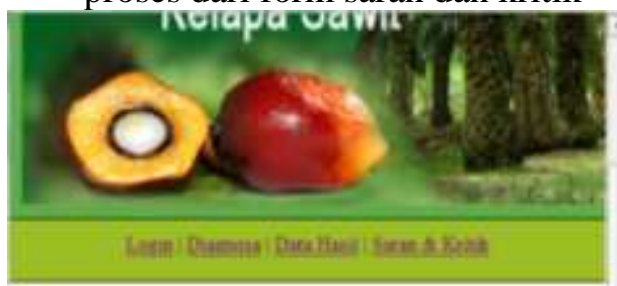

Kritik dan Saran | lihat saran

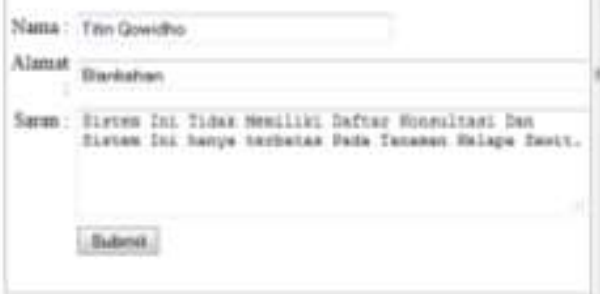

\section{Gambar IV. 5 Tampilan Saran dan Kritik}

\section{KESIMPULAN DAN SARAN 5.1 Kesimpulan}

Dari hasil pengujian sistem yang telah dilakukan, maka dapat diambil beberapa kesimpulan diantaranya sebagai berikut :

1. Sistem pakar ini efektif membantu pengguna untuk mendiagnosa awal gejala penyakit pada tanaman kelapa sawit

2. Sistem pakar ini sangat berguna untuk menggantikan pakar-pakar yang tidak bisa memberikan informasi seperti solusi penanganannya kepada penyuluh petani tanaman kelapa sawit 
3. Pemanfaatan teknologi internet sebagai alat konsultasi online cukup membantu tugas seorang pakar tanaman kelapa sawit.

\subsection{Saran}

Berdasarkan kesimpulan diatas, penulis menggemukakan beberapa saran yang diharapkan akan dapat menjadi bahan pertimbangan yaitu:

1. Untuk perbandingan aplikasi ini dapat menggunakan metode Topsis.

2. Pembahasan sistem pakar untuk mendiagnosa penyakit pada tanaman kelapa sawit ini hendaknya dapat diperluas kepenyakit-penyakit tanaman kelapa sawit lain tidak hanya terbatas pada penyakit tanaman kelapa sawit yang disebabkan biotik saja.

3. Di dalam sistem pakar diagnosa penyakit tanaman kelapa sawit ini sebaiknya diberikan petunjuk atau arahan yang dapat membantuk user untuk mengoperasikan program ini.

4. Penulis menyerahkan untuk meneliti selanjutnya sistem ini bisa dikembangkan, bukan hanya dapat mendiagnosa penyakit tanaman kelapa sawit tapi dapat mencangkup seluruh diagnosa penyakit tanaman yang ada seperti tanaman padi, cabai, tebu, karet, dan jeruk. Sehingga program dapat dipergunakan secara optimal.

\section{DAFTAR PUSTAKA}

Adi Nugroho, Prabowo, Unified Modeling Language (UML), Analisis dan Perancangan Berbasis Objek, Penerbit Andi Yogyakarta, 2011.

Alexander F.K.Sibero, Pengertian Situs Web, Cetakan Pertama, Jakarta, 2011

Muhammad Arhami, Pengetian Sistem Pakar, Penerbit
Andi, Yogyakarta, 2005.

Putranto Adi, Pengertian Tanaman Kelapa Sawit, Penerbit Pustaka Baru Press, Cetakan Pertama, Yogyakarta, 2012

Suyanto Risza, Pengertian Pengendalian Penyakit Tanaman Kelapa Sawit, Penerbit Kanisius, Yogyakarta, 1994

T.Sutojo, Edy Mulyanto, Vincent Suhartono, Struktur Sistem Pakar, Penerbit Andi, Yogyakarta, 2011.

Wahyu Gunawan, Pengertian Database, Penerbit Genius Publisher, Cetakan Pertama, Yogyakarta, 2010

Wahyu Gunawan, Pengertian PHP, Penerbit Genius Publisher, Cetakan Pertama, Yogyakarta, 2010.

(http://www.arokhman.blog.unsoed.ac.id /files/2009/05/diagnosis-dalam-po.pdf)

Diakses tanggal 05 mei 2009

(http://www.elib.unikom.ac.id/files/disk1 1497/jbptunikompp-gdl-enengsurya24839-2-unikom_e-i.pdf)

Diakses tanggal 08 September 2012

(http://www.rolliawati.dosen.narotama. ac.id/files/2011/11/ES4probabilitas.pdf) DIakses tanggal 11 November 2011

(http://www.sitarokab.go.id/downlotperd a.php? file $=2 \% 20$ definisi $\% 20$ dan $\% 20$ si mbol\%20Flowchart.pdf)

Diakses tanggal 14 september 2009, 